\title{
SPORT CONSCIOUSNESS AND BEHAVIOR OF JAPANESE PEOPLE
}

\author{
Takao ASADA \\ Tokyo University of Education \\ Akio KATAOKA \\ Tsukuba University
}

\begin{abstract}
In order to try to stratify the people in their attitudes toward sports and to clarify the conceptual gaps in the consciousness and behavior between the ordinary people and sport instructors, two extensive surveys were conducted by the present investigators on $4,0-40$ general people selected from 202 localities using the probablity proportionate sampling and 1,405 sport instructors randomly sampled from the list of the registered sports trainers in JASA. (1) Data was collected from the general people by the direct interview method and rom the sport instructors by the questionnaire method (mailed), both of which were administered in 1973. The results and discussions on the following topics are briefly presented in this report: (1) patterns of sport behavior, (2) stratifications of sport population, (3) norms of sport conduct, and (4) background of the people's sport behavior.

(1) JASA...... Japan Amateur Sport Association, Tokyo, Japan.
\end{abstract}

\section{Purposes of Study}

The purposes of this study were twofold; first. to try to stratify the Japanese people in their attitudes toward and behavior in sports by the analysis of their sport consciousness with its related concepts, and second to make clear the existing gap and its underlying facts to be found beween the sport consiousness and behavior of the ordinaly people (the receiver) and those of the sport instructors (the giver) through the analysis of the current involvement of the intructors in people's actual participation in sports; this was inteded to be viewed from the individual participants.

Followings are the hypotheses set up in this study:

(1) Individual's sporting life is determine d bi-factorily; one is the subjective (endogenous) factors such as worthwhile living, health, need and interest, knowledge and skill of sports, willingness to do sports, attitude, habit, and experience; the environmental (exoge- 
nous) factors such as leisure time, types of activity, facility, leadership, family and playmates in one's occupation, sport-mindedness in a community, income, and so on.

(2) Both subjective (endogenous) factors and environmental (exogenous) factors lend different impacts on the individual's sport consciousness and behavior depending upon his developmental stage and/or social status.

(3) Therefore, each generation comes to have different mode of sport consciousness and behavior. However, even so, there appears to be an identical modality of sport consciousness and behavior even among people of varied age groups and under different environmental situations.

In this paper some of the characteristics of sport consciousness and behavior of Japanese people are briefly presented being based upon the data obtained from the present authors' surveys.

\section{Subjects and Methods}

(1) General population survey

In this study totally 4,040 subjects were selected from 202 localities by the application of the probability proportionate sampling method to the total porpulation of ages ranged from 15 to 64 years old. The collection of data was made by the face-to-face interview method in the period of August through October in 1973. The ratio of response was 71.7 per cent: 1,374 men and 1,525 women.

(2) Survey on sport instructors

To obtain subjects for this category random sampling was made at an equal interval in the directory of the sport instructors and trainers registered to the Japan Amateur Sport Association. A questionnaire sheet was mailed to and returned from each subject in Setember, 1973. The ratio of response was 90.0 per cent; 1,265 men and 140 women (all inclusive).

\section{Contents of the Surveys}

(1) Demographic survey of sport participation

The total of 256 questions were asked in the following; 1) type and level of basic sport skill, 2) places where one played in his elementary school years, 3) sport clubs to which one belonged in his school years, 4) experience of sport instruction, 5) participation in competitions, 6) enjoyment in sport paticipation, 7) effects of sport, 8) disadvantages in sport participation, 9) opinion about sports, 10) changes in the situations for sports in the past five years, 11) present health condition, 12) objectives to improve one's physical fitness, 13) opinion about the community sports, 14) abilities gained from sport participation, 15) desires in sport participation, 16) need and expectation for sport life, 17) nation's future in ten years, 18) status in sports, and 19) level of economic condition. etc.

(2) Survey on sport instructors

The following items were surveyed;1) present health status, 2) places where one played in his elementary school pears, 3) sport clubs to which one belonged in his school years, 4) interscholastic competitions in which one participated, 5) groups and activities one 
instructed, 6) facilities available to one's instruction, 7) competitions in which the members in his charge participated, 8) aims of instructing sports, 9) management of sport groups, 10) training programs for the group in his charge, 11) monetary rewards from his instruction, 12) utilization of sport certificates, 13) self-coordination of his instruction, buisiness and evaluation by others and personality, 14) sport in which one is presently participating, 15) attendence to training courses, 16) ideals and technics of instruction, 17) relationship with his group members, 18) opinion of senior instructors, 19) types of instructors (ideal and expected), 20) willingness as a sport instructor, 21) enjoyment in sports, 22) effects of sports, 23) disadvantages in sport participation, 24) emphasis in improving physical fitness, 25) opinion about sports, 26) desires in sport participation, 27) need and expectation for sport life, 28) opinion about the community sports, 29) hope for sports, 30) nation's future in ten years and 31) annual income, etc.

\section{Results and Discussion}

(1) Patterns of sport behavior

Fundamental exercises such as long distance walking, calisthenics (for 3 minutes), bicycling (for 30 minutes) for both sexes, and dancing (for 10 minutes) for only women, were popularly performed in all age groups, but other fundamental exercises which require total body endurance, strength, power, and certain level of sport skill were conducted at a less degree by age groups of 20 years and older; especially, participation in those activities appeareed to decline after the middle age. Therefore, it would be necessary to ensue some procedures to hold such declining trends, and also hoped to substantialize and operationally organize those fundamental activities which are still popularly performed in daily life depending on the local characteristics.

As to the people's experiences in sports skills, the younger generation showed a tendency to prefer new activity skills such as ball games, and gymnastics which are included in the school teaching subjects, and bowling and skate which are pursued as leisure sprts; however, there existed marked fluctuations in participation among sport activities. On the contrary, such skills of pre-modern activities as judo, kendo, and cross country walking and such leisure activities as ski and golf enjoy relatively stable participation by all age groups.

The younger the generation is the more they experience competitions in sports, and yet in big games and tournaments. As the consequence, stratification of sport participation derives from these tendencies. As those individuals who have low skill of sports tend to dislike a game which has an association with win or loss, the sport stratification is further determined by this psychological tendency far before one participate in actual competition.

Comparing the sport behavior between the ordinary people and the sport instructors, about a half of the former showed a tendency to prefer various leisure type sports, in which they participated with prevailing modish manner and even with sociable mood; so they tended to transfer easily from one sport to another; whereas, the latter's sport behavior was characterized by their specialization in sport, so that they stayed to participate in certain type of sports. As having this specific traits in sports, the latter's sport behavior is supposed 
to be based on their servitude toward sports and the concept of character building through participation in sports.

Enjoyment of sports experienced by the general people was found to be far less in its quality and quantity than that experienced by the sport instructors. The general people intend to participate in sports with shallow-rooted coceptualization of sports; that is they look for mere enjoyment in sports in order to escape from hard daily life and to find a relief in routine jobs. Generally speaking, when viewed from its relationship with the self, the sport consciousness of the ordinary people in Japan seems to be remarkably low. This might have some relations to their low evaluation of sport in a community and to the trends found in the nation's sport population.

While individuals with this sort of sport experiences are estimated to exist from one million to ten million in certain kind of sports, it seems to be necessary to provide for some measures to make this latent sport population be visuable placing the main emphasis upon the younger generation. The time to do so appears to be already ripened.

(2) Stratitication of sport population

For men, the total figure of those who once belonged to the champion sport class $(5,130,000)$ and those of the club sport class $(1,758,000)$ had reached as many as $22,710,000$. At present, the total number of people who belong to these two categories declind to $3,820,000$ because the rest of men $(18,890,000)$ moved into the leisure sport class, the sport spectator class and the sport apathy class. Tables 1 and 2 show the rates of differnces between the past, and the present in the number of participants in the stratified sport classes for each age group. From these two tables, it is apparent that the club sport class suffered marked decrease in both man and women.

Table 1. Mobility in Sport Classes for Men (Present-Past: School Days)

\begin{tabular}{|c|c|c|c|c|c|c|c|c|c|c|c|}
\hline Age Groups & $15 \sim 19$ & $20 \sim 2$ & $5 \sim$ & $0 \sim 3$ & $5 \sim 39$ & $40 \sim 44$ & $45 \sim 49$ & $50 \sim 54$ & $55 \sim 59$ & $0 \sim 64$ & Total \\
\hline Numbers & 161 & 155 & 168 & 157 & 159 & 166 & 138 & 104 & 95 & 71 & 1374 \\
\hline \multicolumn{12}{|l|}{ Classes $(\%)$} \\
\hline Sport Apathy Class & 14. 3 & 12.9 & 16.7 & 12.8 & 11.9 & 17.5 & 13.1 & 14. 3 & 26. 9 & 33. 8 & 15.5 \\
\hline Sport Spectator Class & 12.5 & 11.0 & 8. 3 & 8. 3 & 12.5 & 14.5 & 12.4 & 4. 8 & 19.0 & 16.9 & 11.7 \\
\hline Sport Participation Class & 0.6 & & 0.6 & 10.2 & 1.3 & -2.4 & -0.7 & 4. 8 & -16.8 & -11.3 & -0.4 \\
\hline Gymnastics-for-Health Class & -1.2 & 3. 2 & 5. 9 & 7.0 & 6.3 & 0.6 & 5.0 & 13. 5 & 11.6 & -5.6 & 5.2 \\
\hline Leisure Sport Class & 3. 4 & 36.8 & 35.7 & 30.0 & 34. 0 & 27.5 & 10.2 & 8.7. & 11.6 & 4. 3 & 21.5 \\
\hline Club Sport Class & -33.6 & -47.1 & -50.6 & -50.6 & -51.0 & -38.0 & -28.3 & -36.3 & -29.5 & -31.0 & -41.0 \\
\hline Champion Sport Class & -6.2 & -16.8 & -17.2 & -14.5 & 9.0 & -12.4 & -12.4 & 9.6 & -14.7 & -7.0 & -12.6 \\
\hline Others & 0.6 & & & & 0.6 & -0.6 & 0.7 & -1.0 & 2.1 & 0 & \\
\hline
\end{tabular}


Table 2. Mobility in Sport Classes for Women (Present-Past : School Days)

\begin{tabular}{|c|c|c|c|c|c|c|c|c|c|c|c|}
\hline Age Groups & $\mid 5 \sim 19$ & $20 \sim 24$ & $5 \sim 29$ & $30 \sim 34$ & $35 \sim 39$ & $\mid 0 \sim 44$ & $45 \sim 49$ & $50 \sim 54$ & $55 \sim 59$ & $60 \sim 64$ & Total \\
\hline Numbers & 161 & 177 & 194 & 208 & 183 & 156 & 144 & 129 & 96 & 77 & 1525 \\
\hline \multicolumn{12}{|l|}{ Classes(\%) } \\
\hline Sport Apathy Class & 13.7. & 24. 8 & 30.4 & 35.1 & 30.6 & 23.7 & 25. 0 & 31.0 & 31.3 & 23. 3 & 27. 2 \\
\hline Sport Spectator Class & 8.7 & 8.4 & 8. 3 & 7.2 & 7.7 & 7.6 & 16. 0 & 10.9 & 8. 3 & 9.1 & 9.0 \\
\hline Sport Participation Class & -3.7 & -4.5 & -7.7 & -3.8 & -0.6 & -5.1 & -17.4 & $\mid-9.3$ & -15.6 & -10.4 & -7.0 \\
\hline Gymnastics-for-Health Class & 5.6 & 3. 9 & 5.6 & 0.6 & 0.6 & 3. 2 & -2.8 & $\mid-2.4$ & 4. 2 & 3. 9 & 2.1 \\
\hline Leisure Sport Class & 13. 7 & 22.0 & 22. 2 & 17.8 & 8. 1 & 4. 4 & 8. 3 & -0.8 & 1.1 & -3.9 & 11.3 \\
\hline Club Sport Class & -35.4 & -46.3 & -47.9 & -48.6 & -43.2 & -31.4 & -22.9 & -27.1 & -24.0 & -20.8 & -37.3 \\
\hline Champion Sport Class & -3.1 & -8.5 & -10.8 & -7.7 & -3.3 & -2.0 & -6.3 & -2.3 & -5.2 & -1.3 & -5.5 \\
\hline Others & 0.6 & & & -0.4 & & -0.7 & 0 & 0 & 0 & & -0.1 \\
\hline
\end{tabular}

Although women show similar trend to that of men, the different point is that in the past they slready had a large number of people both in the sport apathy class and the sport spectator class. So, it is a problem that there still exists a tendency to move into the sport apathy class, which is a prevailing tendency found in the post adolescent ages in which some are already become mothers.

The champion sport class consists of the persons who once belonged to athletic squads in their school years, and, in the same way, the club sport class consists of the individuals who belonged to so-called nominal or recreational athletic clubs. Therefore, the latter class seems not to have sufficient level of sport skills with which they shall be able to enjoy sports after school. This may explain the cause for the marked decline in the current status of the club sport class. And yet, if thinking about the fact that about 35 per cent of the pre-adolescent age groups are dropping out from the sport club activities in the compulsory school years, this class shall be composed of many persons who experienced only primary level of skill in the early part of their lives and, moreover, who quit their practices on a, half way to their completion.

The leisure sport class tends to participate in golf, bowling, softball, and ski which are all excluded from the regular physical education subjects with the exception of baseball using a rubber-made ball. It means that this class' conduct in sports is dependent on the leisure industry, and, in turn, it reveals the poorness of their sport activities when practiced in the public facilites. This seems to lead them to socially higher class type of sport clubs.

As to the age characteristics for each sport class, groups of over 45 years old have fewer population in the champion sport class and the club sport class due to the fact that these groups had passed through their schoolings before the transference period of the revision of the educational system in Japan; whereas, the groups under 44 years old have 
Table 3. Classified Sport Population for Men (Unit : 1, 000)

\begin{tabular}{|c|c|c|c|c|c|c|c|c|c|c|c|}
\hline Age Groups & $15 \sim 18$ & $20 \sim 24$ & $25 \sim 29$ & $30 \sim 34$ & $35 \sim 39$ & $40 \sim 44$ & $45 \sim 49$ & $50 \sim 54$ & $55 \sim 59$ & $60 \sim 64$ & Total \\
\hline Total Numbers & 4149 & 5136 & 4737 & 4440 & 4210 & 3972 & 3346 & 2316 & 2051 & 1879 & 36236 \\
\hline \multicolumn{12}{|l|}{ Classes } \\
\hline Sport Apathy Class & 722 & 894 & 876 & 821 & 846 & 1148 & 947 & 845 & 734 & 926 & 8852 \\
\hline Sport Spectator Class & 568 & 663 & 535 & 511 & 581 & 767 & 559 & 266 & 476 & 423 & 5549 \\
\hline Sport Participation Class & 411 & 596 & 663 & 622 & 425 & 552 & 509 & 378 & 109 & 79 & 4344 \\
\hline Gymnastics-for-Health Class & 207 & 298 & 483 & 453 & 425 & 477 & 435 & 424 & 324 & 265 & 3793 \\
\hline Leisure Sport Class & 411 & 2054 & 1601 & 1501 & 1722 & 993 & 679 & 357 & 324 & 159 & 9801 \\
\hline Club Sport Class & 1365 & 565 & 483 & 453 & 131 & 95 & 144 & 44 & 43 & 26 & 3349 \\
\hline Champion Sport Class & 411 & 67 & 28 & 84 & 80 & 0 & 47 & 0 & 0 & 0 & 717 \\
\hline Others & 50 & 0 & 28 & 0 & 0 & 0 & 23 & 0 & 43 & 0 & 144 \\
\hline
\end{tabular}

Table 4. Classified Sport Population for Women (Unit : 1,000 )

\begin{tabular}{|c|c|c|c|c|c|c|c|c|c|c|c|}
\hline Age Groups & $15 \sim 19$ & $20 \sim 24$ & $25 \sim 29$ & $30 \sim 34$ & $35 \sim 39$ & $40 \sim 44$ & $45 \sim 49$ & $50 \sim 54$ & $55 \sim 59$ & $60 \sim 64$ & Total \\
\hline Total Numbers & 4017 & 5160 & 4824 & 4500 & 4224 & 3959 & 3518 & 2959 & 2485 & 2231 & 37877 \\
\hline \multicolumn{12}{|l|}{ Classes } \\
\hline Sport Apathy Class & 599 & 1631 & 2041 & 1926 & 1939 & 1928 & 1833 & 1790 & 1528 & 1390 & 16603 \\
\hline Sport Spectator Class & 374 & 552 & 622 & 518 & 579 & 582 & 612 & 506 & 335 & 319 & 4999 \\
\hline Sport Participation Class & 699 & 614 & 323 & 500 & 507 & 507 & 292 & 207 & 129 & 87 & 3865 \\
\hline Gymnastics-for-Health Class & 325 & 464 & 545 & 369 & 439 & 432 & 317 & 252 & 363 & 377 & 3883 \\
\hline Leisure Sport Club & 675 & 1398 & 1095 & 932 & 667 & 455 & 440 & 160 & 104 & 29 & 2955 \\
\hline Club Sport Class & 996 & 495 & 101 & 194 & 68 & 0 & 25 & 24 & 0 & 29 & 1932 \\
\hline Champion Sport Class & 301 & 0 & 24 & 23 & 0 & 24 & 0 & 0 & 0 & 0 & 372 \\
\hline Others & 48 & 0 & 72 & 45 & 21 & 24 & 0 & 24 & 25 & 0 & 259 \\
\hline
\end{tabular}

more people who experienced club sport activities. Because of this latter fact, groups under 44 years old seem to reveal that more people who moved from the club sport class to the leisure sport class and even to the sport apathy class than the groups over 45 years old.

This tendency of people toward leisure seems to have some relationships with the so-called other-directedness and/or upper-directedness in our today's information society or consumer society. Although the upper-directedness must be supported by a strong need, in this case, it may well be said that this tendency is supported by people's desire rather than 
need. In fact, this upper-directedness of people does not come up to be shown straight-forwardedly. People are only longing for decent style of life, even in their sport conducts. Therefore, this urge for life makes people directed toward leisure and spectator sports.

Table 5 shows the relationships between sport classes and sport participations (over 5 per cent) and Table 6 shows an estimated sport populations for selected sport activities in Jappn. From each of the tables, it is apparent that school physical education subjects as currently popular leisure sport activities furnish a strong influence on the trend.

Table 5. Sports Participated in by More than 5\% of Population for Each Sport Class (At present)

\begin{tabular}{|c|c|c|c|c|}
\hline Classes & Men & & Women & \\
\hline Sport Spectator Class & $\begin{array}{l}\text { Baseball } \\
\text { Sumo } \\
\text { Volley Ball }\end{array}$ & $\begin{array}{r}50.0 \\
9.2 \\
6.8\end{array}$ & $\begin{array}{l}\text { Volley Ball } \\
\text { Baseball } \\
\text { Bowling } \\
\text { Sumo }\end{array}$ & $\begin{array}{r}31.2 \\
22.8 \\
10.4 \\
6.4\end{array}$ \\
\hline $\begin{array}{l}\text { Sport Participation } \\
\text { Class }\end{array}$ & $\begin{array}{l}\text { Baseball } \\
\text { Softball } \\
\text { Volley Ball } \\
\text { Track \& Field } \\
\text { Baseball }\end{array}$ & $\begin{array}{r}21.4 \\
15.7 \\
15.7 \\
12.6 \\
5.7\end{array}$ & $\begin{array}{l}\text { Volley Ball } \\
\text { Softball } \\
\text { Ping Pong } \\
\text { Track \& Field }\end{array}$ & $\begin{array}{r}46.8 \\
12.2 \\
10.9 \\
7.9\end{array}$ \\
\hline $\begin{array}{l}\text { Gymnastics-For-Health } \\
\text { Class }\end{array}$ & $\begin{array}{l}\text { Free Gymnastics } \\
\text { Ping Pong } \\
\text { Baseball } \\
\text { Softball } \\
\text { Bowling }\end{array}$ & $\begin{array}{r}26.6 \\
11.2 \\
7.6 \\
7.0 \\
6.3\end{array}$ & $\begin{array}{l}\text { Free Gymnastics } \\
\text { Volley Ball } \\
\text { Bowling }\end{array}$ & $\begin{array}{r}42.6 \\
16.8 \\
7.7\end{array}$ \\
\hline Leisure Sport Class & $\begin{array}{l}\text { Golf } \\
\text { Bowling } \\
\text { Baseball } \\
\text { Softball } \\
\text { Skiing }\end{array}$ & $\begin{array}{r}20.3 \\
20.3 \\
15.4 \\
7.6 \\
6.5\end{array}$ & $\begin{array}{l}\text { Bowling } \\
\text { Volley Ball } \\
\text { Skiing } \\
\text { Golf } \\
\text { Ping Pong }\end{array}$ & $\begin{array}{r}44.8 \\
11.3 \\
7.1 \\
6.3 \\
5.5\end{array}$ \\
\hline Club Sport Class & $\begin{array}{l}\text { Baseball } \\
\text { Ping Pong } \\
\text { Baseball } \\
\text { Volley Ball } \\
\text { Soccer } \\
\text { Kendo } \\
\text { Basket Ball }\end{array}$ & $\begin{array}{r}13.1 \\
9.8 \\
9.8 \\
7.3 \\
7.3 \\
6.7 \\
5.2\end{array}$ & $\begin{array}{l}\text { Volley Ball } \\
\text { Tennis } \\
\text { Basket Ball } \\
\text { Tennis } \\
\text { Badmington } \\
\text { Ping Pong }\end{array}$ & $\begin{array}{r}39.5 \\
11.8 \\
9.2 \\
5.3 \\
5.3 \\
5.3\end{array}$ \\
\hline Champion Sport Class & $\begin{array}{l}\text { Baseball } \\
\text { Soccer } \\
\text { Kendo } \\
\text { Skiing } \\
\text { Volley Ball }\end{array}$ & $\begin{array}{r}14.8 \\
14.8 \\
14.8 \\
11.8 \\
7.4\end{array}$ & $\begin{array}{l}\text { Bolley Ball } \\
\text { Tennis } \\
\text { Softball } \\
\text { Skiing }\end{array}$ & $\begin{array}{r}40.0 \\
20.0 \\
20.0 \\
6.7\end{array}$ \\
\hline
\end{tabular}


Toble 6. Estimated Sport Population for Each Sport in Japan (Unit : 1, 000) (At Present)

\begin{tabular}{|c|c|c|}
\hline Population & Men & Women \\
\hline Up to 599 & & Volleyball \\
\hline Up to 399 & Baseball & Bowling \\
\hline Up to 299 & Bowling, Golf & \\
\hline Up to 199 & $\begin{array}{l}\text { Softball, Volleyball, Ping Pong, } \\
\text { Calisthenics }\end{array}$ & Calisthenics Ping Pong Baseball \\
\hline $50-100$ & $\begin{array}{l}\text { Track \& Field, Skiing, Soccer. Mt. } \\
\text { Climbing, Swimming, Kendo, Sumo, } \\
\text { Light Exercise }\end{array}$ & $\begin{array}{l}\text { Softball, Tennis, Skiing Track \& Field, } \\
\text { Babmington Golf, Light Exercises }\end{array}$ \\
\hline $10-50$ & $\begin{array}{l}\text { Basket Ball, Tennis, Judo, Ice Skating, } \\
\text { Hiking, Gymnastics, Tennis, Badmigton, } \\
\text { Boxing, Karate }\end{array}$ & $\begin{array}{l}\text { Basket Ball, Swimming, Mt. Climbing, } \\
\text { Sumo, Hiking, Ice Skating Tennis, } \\
\text { Gymnastics, Folk Dance }\end{array}$ \\
\hline $5-10$ & $\begin{array}{l}\text { Wrestling, Handball, Folk Dance, } \\
\text { Kyudo, Weight Lifting, Archery, } \\
\text { Ciclying, Ruggby, Ice Hockey }\end{array}$ & Ciclying, Archery \\
\hline 2. 5-5 & $\begin{array}{l}\text { American Football, Camping, Rifle } \\
\text { Clay Pigeon Shooting }\end{array}$ & $\begin{array}{l}\text { Baseball, Wrestling, Handball, Boxing, } \\
\text { Kendo, Kyudo, Camping }\end{array}$ \\
\hline $\begin{array}{l}\text { Less Than } \\
2.5\end{array}$ & $\begin{array}{l}\text { Fencing, Aikido, Field Hockey, } \\
\text { Yecht, Horsemanship, Biciclying, } \\
\text { Tenipon, Panpon, Canoe }\end{array}$ & $\begin{array}{l}\text { Weight Lifting, Fencing Ruggby, } \\
\text { Ameriacan Football Karate, Rifle, Boat, } \\
\text { Judo, Ice Hockey, Horsemanship, Canoe, } \\
\text { Biciclying, Aikido, Clay pigeon } \\
\text { shooting, Tenipon, Panpon, Yacht } \\
\text { Field Hockey. }\end{array}$ \\
\hline
\end{tabular}

(3) Norms of sport conduct

The degree of a normative conduct in a certain behavior pattern may, in general, be represented by the extent to which one's rightful conduct is set against to the extent of the deviation of the other's conduct from the desired behavior pattern in a certain sport situation. Therefore, it might be able to think that the degree of the norms of sport conducts in general public could be calculated from the following equation:

(Expected value (\%) of sports by the sport instructors-Expected value (\%) of sports by the general public) $\div$ Expected value $(\%)$ of sports by the general public $=$ The degree of norms of sports

Table 7 shows the degree of norms calculated from the above equation, which represents the quality of sports viewed by the Japanese people.

1) Norms for men. The norms of sports for men are enhanced with the increasing ages; however, norms of such qualities as planning ability, cooperativeness, group solidarity, sociability, etc. are conceived higher by the age groups of 20 to 24 years old than by the 
Table 7. Conceptual Norms and Characteristics of Sports

\begin{tabular}{|c|c|c|c|c|c|c|c|}
\hline \multirow{2}{*}{ Sexes } & \multicolumn{5}{|c|}{ Men } & \multicolumn{2}{|c|}{ Women } \\
\hline & $20 \sim 24$ & $25 \sim 34$ & $35 \sim 49$ & $50 \sim 59$ & $60 \sim 65$ & $\begin{array}{l}\text { Under } \\
39\end{array}$ & $\begin{array}{c}\text { Over } \\
40\end{array}$ \\
\hline \multicolumn{8}{|l|}{ Norms } \\
\hline Independency & 0.21 & 0.24 & 0.33 & 0.69 & 0.98 & 0.41 & 0.57 \\
\hline Creativity & 0.34 & 0.54 & 0.48 & 1.02 & 1.83 & 0.65 & 0.92 \\
\hline Planning Ability & 0.36 & 0.25 & 0.31 & 0.19 & 1.61 & 0.49 & 0.65 \\
\hline Leadership & 0.41 & 0.42 & 0.53 & 0.91 & 1.12 & 1.00 & 0.99 \\
\hline Sense of Justice & 0.09 & 0.81 & 0.16 & 0.43 & 0.65 & 0.16 & 0.59 \\
\hline Co-operation & 0.17 & 0.10 & 0.09 & 0.37 & 0.54 & 0.18 & 0.37 \\
\hline Concentration & 0.13 & 0.13 & 0.09 & 0.36 & 0.79 & 0.12 & 0.37 \\
\hline Strong Will & 0.04 & 0.14 & 0.17 & 0.42 & 0.69 & 0.24 & 0.41 \\
\hline Prompt decision & 0.08 & 0.09 & 0.15 & 0.49 & 0.61 & 0.09 & 0.31 \\
\hline Solidarizy & 0.14 & 0.01 & 0 & 0.27 & 0.54 & 0.05 & 0.16 \\
\hline Competitiveness & -0.33 & -0.19 & -0.24 & -0.02 & -1.13 & -0.20 & -0.02 \\
\hline Heve Regular Habit & 0.15 & 0.16 & 0.21 & 0.41 & 0.48 & 0.12 & 0.13 \\
\hline Prudent & 0.03 & -0.07 & 0.08 & 0.33 & 0.74 & 0.08 & 0.18 \\
\hline Courtesy & 0.24 & 0.14 & 0.14 & 0.35 & 0.42 & 0.11 & 0.10 \\
\hline Sociability & 0.09 & 0.03 & -0.01 & 0.22 & 0.50 & -0.40 & 0.04 \\
\hline
\end{tabular}

Remarks : Figures in the table were calculated through the following formula.

$\{$ Leaders $(\%)$-Nations $(\%)\} \div$ Nnations $(\%)=$ Nonrm

age groups of 25 to 49 . Specifically speaking, norms on competitiveness and strong will are conceived low by the younger age groups (under 24 years old) and norms on creativity, planning ability, leadership, and competitiveness are conceived high in the older age groups (over 60 years old).

The discrepancy in the norm on competitiveness, which is thought of as one of the typical characteristics of sports, between the age groups of under 59 years old and the group of over 60 years old seems to be derived from the difference in their thoughts and expectations to the present day sports. This, in turn, appears to make a large gap in the inclination toward sports between the sport instructors and the ordinary people and make it wider along with the age increment in the middle and older ages. The norm on the planning ability shows a similar trend.

2) Norms for women. In general, women too shows similar modalities in the norms to those for man; that is, the norms of the qualities of sports in women increase linearly with the increment of age. 
There was no differerence in the norm on leadership between the age groups of under 39 years old and over 40 years old, which was found to be low. Therefore, when conducting women's sport activities, it seems necessary to provide much more leadership than for men. This means the marked lacking of leadership in women's sports. And also, there were lackings of creativity, planning ability, self-independency, strong will, etc. in women.

Low modality of the norm on competitiveness in women under 39 years of age is the same trend as found in men. This seems to be one of the distinguished characteristics of sport behavior to be found in the present day society.

(4) Background of the people's sport behavior

1) Cognition of the body. People's desired body image consists of the body with qualities as strong resisting power against sickness, good motor ability, and general endurance (to these men added sturdiness and women flexibility). Though people well recognize the life-long necessity for sport participation, about 30 per cent of them are losing their health due to the lack of physical exercises and about 20 per cent of the sport instructors suffered ill health due to their daily hard workings. Therefore, many people are able to have a better understanding of how the lack of exercise causes ill health.

In order to help people to develop their body as they desired, the sport instructors need to let the people understand the necessity for doing certain amount of physical exercise regularly in one's daily living and to ensure their actual practices.

2) Conceptualization of the characteristics of spors and its effects. As to the concept of the abilities to be obtained through the sport participation, no difference was found between the general public and the sport instructors. Their concepts on the characteristics and effects of sports are almost identical, but, to be more specific, the sport instructors give slightly more of the characteristics adding such item as self-independence.

There are only few women who recognize the effects of spors; this may due to their lack of experience in sport participation. However, women sport instructors show their recognition of similar effects of sports to those conceptualized by their male counterpart.

3) Leisure time. The younger generation shows strong needs for sports, but they are having difficulty in securing their free time. Whereas, the older generation easily obtains their free time, but they are not using it for sports. Generally speaking, the leisure consciousness (increase in free time) will be a future problem for the ordinary people.

On the contrary, the sport instructors endeavor to squeeze their time for sports out of their daily living, so that many of them always have some feeling of the shortage of time.

4) Facilities (clubs) and places to do sports. It is a common understanding, without any diferences in age and sex, that people are tended to do sports in outdoors and in family circles. This line of interest and concern is stronger in the sport instructors (mainly in their 30s) than in the ordinary people.

People are requiring the sport facilities to be set up with following conditions; short distance from one's residence, surrounded by the natural environmental settings, reasonable charge, availability at one's will, possibility of substantial physical activity, and safety. As to the safety, the sport instructors stongly require for its insurance because of their instructi- 
onal responsibility.

Play facilitities (clubs) in local communities are centered around schools; therefore, it is hoped that those school sport facilities are to be allowed for the public use.

5) Play-mates and groups. There are marked differences in group concept between the ordinary people and the sport instructors, especially in the older generations. The instructors prefer heterogeneous grouping (with respect to both age and skill level), while others are inclined to form homogeneous groups and tend to be exclusive to others.

People's concern for membership clubs is still weak regardless of age, but it is becoming stronger in the instructors who are in the middle ages and over. This difference seems to be derived from the fact whether-or-not one having the high level of skill and/or speciality in a certain sport.

The instructors' time for teachihg their sport groups is determined by the conditions of the members' leisure tme; most of them are scheduled from evening through night. Night practices on weekdays are mainly intended to promote the popularlization of sport activity, and the instructors for those are mostly younger ones for men and the middle-aged for women.

Sport groups of popular activities, members of which are mainly consisted of housewives, meet about once a week, but those of competitive sports meet more than three times a week. Age of the instructors for these groups ranged from 25-39 and over 56-65 in both men and women. It is a general understanding that these groups of instructors are supporting the national sport activities in Japan. In general, about 80 per cent of the instructors are conducting some sorts of courses for the general public.

6) Sport instructors. The sport instructors' behavior is supported by their sense of pres- tige in their specialty in a certain type of sports and the awareness of the self as a sport instructor. Their main emphasis in teaching sport groups is put on the entry of their groups in the official tournament, and their basic guidelines for instruction are discussions and autonomy of members for men and the directional method for women.

There are some variations in instructional patterns among different age groups of sport instructors; $i$. e. the patterns tend to change according to increasing stages of age groups of instructors from the competitive type of the younger instructors to the promotional type of the middle-aged and again to the competitive of the older age group of instructors. Although these inclinations of instructors might be derived from the personal characteristics of the sport instructors selected as the subjects in this survey, this trend seems to suggest that the sport instructors are required to have a certain level of sport skills even when teaching popular sport activities; especially, the younger insructors are required to have not only sport skills but also safety-mindedness. There is also a need for a multi-talented sport instructor, who is not necessarilly required to have a certain sport skill, for promoting popular sport among beginners.

From above mentioned trend so-called division of teaching jobs came to be developed among sport instructors depending on their hierarchy in sport competition. This in turn necessitates for each instructor to obtain adequate information concerning the teaching 
contents of his specific sport, Therefore, it appears necessary to provide in-service re-training courses for sport instructors.

As to the insructors' attitudes toward group members, the ordinary people are inclined to dislike the control of their instructors, and people want them to be frank in their instruction; that is, their attitudes toward sports are as it were characterized by their fugetive and pleasure-seeking mannerism, especially in younger generation. To this, the instru- ctors emphasize the importance of courteous manner on the side of group members. In both general people and the sport instructors, the younger generation tends to preferr the frankness in their instsuctors, whereas the elders cherisha courteous manner. But, there is a wide difference in its rate between them.

About 70 per cent of sport instructors give services to the people without receiving payment. Almost all of them suffer deficit in their expenses. Yet, they try to arrange their time to serve as instructors of the training courses in spite of giving inflictions to their jobs and buisiness. However, these handicaps on the side of the insructors seem to be overcome through the direct humane contact establiched between the leadership and the followership in both of them; especially in the younger instrutors, it is overcome by their strong willingness to make progress in their sport activities.

Consaquently, it may well be said that people's sport activities in Japan are strongly supported by the self-sacrificing and willingnass on the side of sport instructors. It is imperative for the national and the local governments to provide fundamental assistance to this line of prople's endeavor on their respective legislative levels.

\section{References}

1) Yasuda, Saburo : Social Statistics, Maruzen, 1972.

2) Yasuda, Saburo, Planning and Analysis in Social Survey, The University of Tokyo Press, 1973.

3) Yasuda, Saburo: Social Survey Handbook, Yuhikaku, 1973.

4) The Committee of Nationlity Survey, The Institute of Mathematical Statistics : Nationality of the Japanese People, Shisedo, 1970.

5) The Committee of Nationality Survey, The Institute of Mathematical Statistics : Nationality of the Japanese People-No. 2, Shiseido, 1970.

6) The Japan Amater Sports Association : Report on the Basic Survey of Sports Participation (19661970), The Japan Amateur Sports Association, 1971.

7) The Japan Amateur Spors Association : Report on the National Sports Survey, The Japan Amateur Sports Association, 1968.

8) The New Machine System Center, The Machine Promoting Association: The Sacial Significance of Industrial Behavior in the Leisure Age. The Leisure Developing Center, 1973.

9) The Course on the Theory in Physical Education, Tokyo University of Education : A Survey on the People's Cognition of Sports and Health. The Japan Amateur Sports Association, 1973.

(All references listed above are written in Japanese.) 